\title{
Binary Mutual Diffusion Coefficients of Isoniazid Aqueous Solutions at (298.15 and 310.15) $\mathrm{K}$
}

\author{
Ana C. F. Ribeiro ${ }^{\dagger}{ }^{\dagger}$ Ana C. G. Santos, ${ }^{*} \dagger$ Victor M. M. Lobo, ${ }^{\dagger}$ Francisco J. B. Veiga, ${ }^{\ddagger}$ Ana M. T. D. P. V. Cabral, ${ }^{\ddagger}$ \\ Miguel A. Esteso, and Ornella Ortona"
}

Department of Chemistry, University of Coimbra, 3004-535 Coimbra, Portugal, Faculty of Pharmacy, University of Coimbra, 3000-295 Coimbra, Portugal, Departamento de Química Física, Facultad de Farmacia, Universidad de Alcalá, 28871, Alcalá de Henares (Madrid), and Department of Chemistry, University of Naples, Federico II, Monte Sant'Angelo, 80126 Naples, Italy

\begin{abstract}
Binary mutual diffusion coefficients measured by the Taylor dispersion method in two different laboratories (University of Naples, Federico II, Italy, and University of Coimbra, Portugal) are reported for aqueous solutions of isoniazid at concentrations from $(0.000$ to 0.100$) \mathrm{mol} \cdot \mathrm{dm}^{-3}$ and at two temperatures (298.15 and 310.15) $\mathrm{K}$. The hydrodynamic radii for the isoniazid in aqueous solution are calculated from the experimental results. In addition, the Hartley equation and the experimental diffusion coefficients are used to estimate activity coefficients for aqueous isoniazid at both temperatures.
\end{abstract}

\section{Introduction}

Tuberculosis (TB), an infectious deadly disease caused by the bacillus Mycobacterium tuberculosis, is a growing international health concern since it is responsible for the death of about 3 million people per year worldwide. ${ }^{1-8}$ Isonicotinic hydrazide (INH, isoniazid), first synthesized by Meyer and Mally in $1912,{ }^{3}$ has been used since the $1950 \mathrm{~s}$ as a first-line antituberculosis drug, characterized by an outstanding minimal inhibitory concentration in the human body [ $(0.1$ to 0.17$)$ $\left.\mathrm{mol} \cdot \mathrm{dm}^{-3}\right]$ and having a high specificity toward Mycobacterium tuberculosis. However, this drug is often administered together with other ones, as currently recommended by international guidelines, ${ }^{1-8}$ once tuberculosis is still resistant, regardless of the existence of multiple classes of antibiotics. For example, from research studies of factors associated with the increasing incidence of this disease in England, ${ }^{7}$ one can conclude that the proportion of cases coinfected with the human immunodeficiency virus (HIV) has increased, migration being the main reason that explains most of the recent trends in tuberculosis in this country. Thus, the global health problems of TB (that is, the increasing rate of prevalence of multidrug resistance (MDR) on this infectious deadly disease) and the high rate of coinfection with persons suffering from the human immunodeficiency virus $(\mathrm{HIV})^{7,8}$ have greatly contributed to the need of developing new, affordable, anti-TB drugs without cross-resistance with known antimycobacterial agents.

Taking into account these facts, we can say that the properties and behavior of such chemical systems are poorly known, even though this is a prerequisite to obtain an adequate understanding and solve these problems of health. In fact, few have taken into account the transport behavior of these isoniazid systems in aqueous solutions. ${ }^{9,10}$ In particular, diffusion coefficients provide a direct measure of molecular mobility, an important

\footnotetext{
* Corresponding author. E-mail: anacfrib@ci.uc.pt. Tel.: +351-239-854460. Fax: +351-239-827703.

Department of Chemistry, University of Coimbra.

$\$$ Faculty of Pharmacy, University of Coimbra.

${ }^{\S}$ Facultad de Farmacia, Universidad de Alcalá

"Department of Chemistry, University of Naples.
}

factor in the preservation of biological materials in different matrices. Thus, this has provided the impetus for the present study of the diffusion of isoniazid in aqueous solutions. No data on mutual diffusion coefficients of isonioazid are available, namely, at (298.15 and 312.15) $\mathrm{K}$-relevant data for in vivo pharmaceutical application-as far as careful literature searches have shown. This paper reports experimental data for mutual diffusion (interdiffusion) coefficients $D$, measured by the Taylor dispersion method, for aqueous solutions of isoniazid at concentrations from ( 0.00 to 0.10$) \mathrm{mol} \cdot \mathrm{dm}^{-3}$ and at temperatures (298.15 and 312.15) K. From our results, it is possible to estimate the behavior of the diffusion of this drug in solution and other important parameters such as the hydrodynamic radius. In addition, the Hartley equation ${ }^{9-14}$ and the measured diffusion coefficients are used to estimate activity coefficients for aqueous isoniazid, contributing this way to a better understanding of their thermodynamic behavior in aqueous solution at different concentrations.

\section{Experimental Section}

Materials. Isoniazid (Sigma, pro analysi $>99 \%$ ) was used as received. The solutions for the diffusion measurements were prepared in calibrated volumetric flasks using bidistilled water. The solutions were freshly prepared and deaerated for about 30 min before each set of runs. The uncertainty on their compositions was usually within $\pm 0.1 \%$.

Procedure. The theory of the Taylor dispersion technique is well described in the literature, ${ }^{15-19}$ and so we only indicate some relevant points on the experimental determination of binary diffusion coefficients, $D$.

The above method is based on the dispersion of small amounts of solution injected into laminar carrier streams of solvent or solution of different composition, flowing through a long capillary tube. ${ }^{15-19}$ For the measurement carried on in Coimbra, the length of the Teflon dispersion tube used in the present study was measured directly by stretching the tube in a large hall and using two high quality theodolytes and appropriate mirrors to accurately focus on the tube ends. This technique gave a tube length of $3.2799( \pm 0.0001) \cdot 10^{4} \mathrm{~mm}$, in agreement 
Table 1. Mutual Diffusion Coefficients of Aqueous Isoniazid Solutions and the Respective Standard Deviations, $D \pm S_{\mathrm{D}}$, at Different Concentrations, $c$, at Two Temperatures

\begin{tabular}{|c|c|c|c|c|}
\hline$c$ & $\Delta c^{a}$ & $T=298.15 \mathrm{~K}$ & $\Delta c^{a}$ & $T=310.15 \mathrm{~K}$ \\
\hline $\mathrm{mol} \cdot \mathrm{dm}^{-3}$ & $\mathrm{~mol} \cdot \mathrm{dm}^{-3}$ & $\overline{D \pm S_{\mathrm{D}} / 10^{-9} \mathrm{~m}^{2} \cdot \mathrm{s}^{-1}}$ & $\mathrm{~mol} \cdot \mathrm{dm}^{-3}$ & $D^{c} \pm S_{\mathrm{D}} / 10^{-9} \mathrm{~m}^{2} \cdot \mathrm{s}^{-1}$ \\
\hline 0.000 & 0.002 & $0.826 \pm 0.004^{b}$ & 0.002 & $1.190 \pm 0.020$ \\
\hline 0.005 & 0.005 & $0.825 \pm 0.006^{b}$ & 0.005 & $1.185 \pm 0.003$ \\
\hline 0.020 & 0.010 & $0.821 \pm 0.004^{b}$ & 0.010 & $1.105 \pm 0.002$ \\
\hline 0.050 & 0.005 & $0.814 \pm 0.002^{c}$ & 0.010 & $1.090 \pm 0.001$ \\
\hline 0.100 & 0.010 & $0.809 \pm 0.001^{c}$ & 0.010 & $1.042 \pm 0.002$ \\
\hline
\end{tabular}

${ }^{a} \Delta c$ represents the difference between the flow and injection solutions, respectively. ${ }^{b}$ Experimental values obtained from the Taylor technique installed in the Department of Chemistry at Coimbra University. ${ }^{c}$ Experimental values obtained from the Taylor technique installed in the Department of Chemistry at Naples University.

with less-precise control measurements using a good-quality measuring tape. The radius of the tube, $0.5570( \pm 0.0003) \mathrm{mm}$, was then calculated from the tube volume obtained by accurately weighing (resolution $0.1 \mathrm{mg}$ ) the tube when empty and when filled with distilled water of known density.

At the start of each run, a 6-port Teflon injection valve (Rheodyne, model 5020) was used to introduce $0.063 \mathrm{~mL}$ of solution into the laminar carrier stream of slightly different composition. A flow rate of $0.17 \mathrm{~mL} \cdot \mathrm{min}^{-1}$ was maintained by a metering pump (Gilson model Minipuls 3) to give retention times of about $1.1 \cdot 10^{4} \mathrm{~s}$. The dispersion tube and the injection valve were kept at (298.15 and 303.15) K $( \pm 0.01 \mathrm{~K})$ in an air thermostat.

For the measurements carried out at Federico II University of Naples, the system was formed by a $20 \mathrm{~m}$ capillary tube with an inner radius of $0.4020( \pm 0.0001) \mathrm{mm}$ connected to a metering pump Watson Marlow 403U/VM2 set at the flowing rate of $0.5 \mathrm{~mL} \cdot \mathrm{min}^{-1}$, and the differential refractometer was Knauer K2301. The capillary tube was inserted into a thermostated water bath, while the entire apparatus was once more thermostated by an air bath. Also, equipment was kept at (298.15 and 303.15) $\mathrm{K}( \pm 0.01 \mathrm{~K})$.

Dispersion of the injected samples was monitored using a differential refractometer (Waters model 2410) at the outlet of the dispersion tube. Detector voltages, $V(t)$, were measured at accurately $5 \mathrm{~s}$ intervals with a digital voltmeter (Agilent 34401 A) with an IEEE interface. Binary diffusion coefficients were evaluated by fitting the dispersion equation

$$
V(t)=V_{0}+V_{1} t+V_{\max }\left(t_{\mathrm{R}} / t\right)^{1 / 2} \exp \left[-12 D\left(t-t_{\mathrm{R}}\right)^{2} / r^{2} t\right]
$$

to the detector voltages. The additional fitting parameters were the mean sample retention time $t_{\mathrm{R}}$, peak height $V_{\max }$, baseline voltage $V_{0}$, and baseline slope $V_{1}$.

\section{Results and Discussion}

The Taylor dispersion equipment was used to measure diffusion coefficients for aqueous solutions of isoniazid at (298.15 and 312.15$) \mathrm{K}$ and at concentrations from (0.00 to 0.10$)$ $\mathrm{mol} \cdot \mathrm{dm}^{-3}$. Table 1 gives the average $D$ value for each carrier solution determined from four profiles, generated by injecting samples that were more or less concentrated than the carrier solution (uncertainties of (1 to 2) \%).

The concentration dependence of the measured diffusion coefficients is accurately represented (standard deviation $<1$ $\%)$ by the linear equation

$$
D=D^{0}[1+A c]
$$

where $D^{0}$ is the diffusion coefficient at infinitesimal concentration. The least-squares values of $D^{0}$ and parameter $A$ are listed in Table 2.
Table 2. Least-Squares Values of Parameters $D^{0}$ and $A$ for the Concentration Dependence of $\boldsymbol{D}$ (Equation 2)

\begin{tabular}{ccccc}
\hline system & $T / \mathrm{K}$ & $D^{0} / 10^{-9} \mathrm{~m}^{2} \cdot \mathrm{s}^{-1} \mathrm{~s}^{-1}$ & $A / 10^{-9} \mathrm{~m}^{2} \cdot \mathrm{s}^{-1}$ & $\sigma^{c}$ \\
\hline Isoniazid & 298.15 & $0.826^{a}$ & -0.289 & $4.114 \cdot 10^{-4}$ \\
& 310.15 & $1.207^{b}$ & -4.567 & $6.668 \cdot 10^{-3}$ \\
\multicolumn{5}{c}{ Values obtained for $c \leq 0.05 \mathrm{~mol} \cdot \mathrm{dm}^{-3 .}{ }^{b}$ Values obtained for $c \leq$} \\
$0.02 \mathrm{~mol} \cdot \mathrm{dm}^{-3 .}{ }^{c}$ Standard deviations.
\end{tabular}

Table 3. Activity Coefficient, $\gamma$, for Aqueous Solutions of Isoniazid Obtained from Equations 2, 3, and 4, Using the $A$ Coefficients Indicated in Table 2

\begin{tabular}{ccc}
\hline$c / \mathrm{mol} \cdot \mathrm{dm}^{-3}$ & $T=298.15 \mathrm{~K}$ & $T=310.15 \mathrm{~K}^{a}$ \\
\hline 0.005 & 0.9986 & 0.9774 \\
0.010 & 0.9971 & 0.9554 \\
0.020 & 0.9942 & 0.9127 \\
0.050 & 0.9856 & --- \\
0.100 & 0.9715 & ---
\end{tabular}

${ }^{a}$ See Table 2.

Also, the concentration dependence of the mutual diffusion coefficient for dilute solutions of nonionic solutes can be given by Hartley's equation ${ }^{9,10}$

$$
D=D^{0}\left(1+\frac{\mathrm{d} \ln \gamma}{\mathrm{d} \ln c}\right)_{T, P}
$$

where $\gamma$ is the thermodynamic activity coefficient of the solute. Combining Hartley's equation and that proposed by Miyajima et al. (eq 4$)^{20}$

$$
\ln \gamma=B c
$$

we obtain

$$
D=D^{0}(1+B c)
$$

for the predicted concentration dependence of the mutual diffusion coefficient of dilute solutions. The activity coefficients can be estimated from the concentration dependence of $D$ using $\mathrm{d}\left(D / D^{0}\right) / \mathrm{d} c=B$, eq 5 and eq 4 (Tables 2 and 3 ). From the decrease observed in the experimental values of this parameter (Table 3), it can be followed that the solute-solute interactions are favored with respect to the solute-solvent ones in this range of concentrations for both temperatures. Those interactions, which can result in the aggregate stabilization, are, however, enhanced for physiological temperature, despite the thermal motion. From that fact, we can assume that the presence of eventual aggregates in those solutions affects mainly the thermodynamic behavior of this drug and less the diffusion behavior. For one possible explanation, we should consider that $D$ is a product of both kinetic (molar mobility coefficient of a diffusing substance, $\left.U_{\mathrm{m}}\right)$ and thermodynamic factors $(c \partial \mu / \partial c$, where $\mu$ represents the chemical potential). Consequently, two different effects can control the diffusion process: the ionic mobility and the gradient of the free energy. These effects can 
Table 4. Hydrodynamic Radius, $a$, of Isoniazid at (298.15 to 310.15) $\mathrm{K}$

\begin{tabular}{ccc}
\hline & $\frac{10^{15} D^{0} \eta^{0} / T}{\mathrm{~m} \cdot \mathrm{s}^{-1} \cdot \mathrm{kg} \cdot \mathrm{K}^{-1}}$ & \\
\hline 298.15 & 2.467 & $0 . \mathrm{nm}$ \\
310.15 & 2.638 & 0.297
\end{tabular}

contribute to the diffusion coefficients in an opposite way, and consequently, from the final balance, one slight alteration of diffusion coefficients with concentration is found.

Hydrodynamic Radius of Isoniazid. The hydrodynamic radius of isoniazid can be estimated from the Stokes-Einstein equation 9 (eq 6)

$$
D^{0}=k_{\mathrm{B}} T / 6 \pi \eta^{0} a
$$

where $k_{\mathrm{B}}$ and $\eta^{0}$ are Boltzmann's constant and the viscosity of pure water at temperature $T$, respectively. ${ }^{21}$ The values of $D^{0} \eta^{0} / T$ and the effective hydrodynamic radius $a$ for (298.15 and 310.15) $\mathrm{K}$ are given in Table 4 . Their variations are, in general, relatively small, $6 \%$, which is slightly higher than the imprecision of the diffusion measurements.

\section{Conclusion}

From the data on binary diffusion measurements, we may conclude that for the studied concentration range the diffusion coefficient is almost constant $(\Delta D \leq 2 \%)$, in contrast with the decrease in the values found for the estimated activity coefficients, mainly at physiological temperature. This leads us to assume the presence of eventual aggregates in those solutions. Diffusion coefficients measured for aqueous solutions of isoniazid provide transport data necessary to model the diffusion for various chemical and pharmaceutical applications.

\section{Literature Cited}

(1) Banerjee, R.; Allen, J.; Westenhouse, J.; Oh, P.; Elms, W.; Desmond, Ed.; Nitta, A.; Royce, S.; Flood, J. Extensively Drug Resistant Tuberculosis in California, 1993-2006. Clin. Infect. Dis. (CID) 2008, $47,450-457$.

(2) Ranguelova, K.; Suarez, J.; Magliozzo, R.; Mason, R. P. Spin Trapping Investigation of Peroxide- and Isonoiazid-Induced Radicals in Mycobacterium tuberculosis Catalase-Peroxidase. Biochemistry 2008, 47 , $11377-11385$.

(3) Scior, T.; Garces-Eisele, S. J. Isoniazid is Not a Lead Compound for its Pyridyl Ring Derivatives, Isonicotinoyl Amides, Hydrazides, and Hydrazones: A Critical Review. Curr. Med. Chem. 2006, 13, 22052219.

(4) Zhao, X.; Yu, S.; Magliozzo, S. Characterization of the Binding of Isoniazid and Analogues to Mycobacterium Tuberculosis CatalasePeroxidase. Biochemistry 2007, 46, 3161-3170.

(5) Camacho-Corona, M. R.; Ramírez-Cabrera, M. A.; Gonzalez-Santiago, O.; Garça-Gonzalez, E.; Palacios, I. P.; Luna-Herrera, J. Activity against Drug Resistant-Tuberculosis Strains of Plants used in Mexican
Traditional Medicine to treat Tuberculosis and Other Respiratory Diseases. Phytother. Res. 2008, 22, 82-85.

(6) Tomioka, H. Current Status of Some Antituberculosis Drugs and the Development of new Antituberculous Agents with Special Reference to their In Vitro and In Vivo Antimicrobial Activities. Curr. Pharm. Des. 2006, 12, 4047-4070.

(7) Crofts, J. P.; Gelb, D.; Andrews, N.; Delpech, V.; Watson, J. M.; Abubakar, I. Investigating Tuberculosis Trends in England. Public Health 2008, 122, 1302-1310.

(8) Golub, J. E.; Astemborski, J.; Ahmed, M.; Cronin, W.; Mehta, S. H.; Kirk, G. D.; Vlahov, D.; Chaisson, R. E. Long-Term Effectiveness of Diagnosing and Treating Latent Tuberculosis Infection in a Cohort of HIV-Infected and At-Risk Injection Drug Users. JAIDS 2008, 49, 532-537.

(9) Erdey-Grúz, T. Transport Phenomena in Aqueous Solutions, 2nd ed.; Adam Hilger: London, 1974.

(10) Tyrrell, H. J. V.; Harris, K. R. Diffusion in Liquids, 2nd ed.; Butterworths: London, 1984.

(11) Ribeiro, A. C. F.; Leaist, D. G.; Lobo, V. M. M.; Esteso, M. A.; Valente, A. J. M.; Santos, C. I. A. V.; Cabral, A. M. T. D. P. V.; Veiga, F. J. B. Binary mutual Diffusion Coefficients of Aqueous Solutions of $\beta$-cyclodextrin at Temperatures from 298.15 to 312.15 K. J. Chem. Eng. Data 2006, 51, 1368-1371.

(12) Ribeiro, A. C. F.; Valente, A. J. M.; Santos, C. I. A. V.; Prazeres, P. M. R. A.; Lobo, V. M. M.; Burrows, H. D.; Esteso, M. A.; Cabral, A. M. T. D. P. V.; Veiga, F. J. B. Binary Mutual Diffusion Coefficients of Aqueous Solutions of $\alpha$-Cyclodextrin, 2-Hydroxypropyl- $\alpha$-cyclodextrin and 2-Hydroxypropyl- $\beta$-cyclodextrin at Temperatures from 298.15 to 312.15 K. J. Chem. Eng. Data 2007, 52, 586-590.

(13) Ribeiro, A. C. F.; Santos, C. I. A. V.; Valente, A. J. M.; Ascenso, O. S.; Lobo, V. M. M.; Burrows, H. D.; Cabral, A. M. T. D. P. V.; Veiga, F. J. B.; Teijeiro, C.; Esteso, M. A. Some Transport Properties of $\gamma$-Cyclodextrin Aqueous Solutions at (298.15 and 310.15) K. J. Chem. Eng. Data 2008, 53, 755-759.

(14) Ribeiro, A. C. F.; Ortona, O.; Simões, S. M. N.; Santos, C. I. A. V.; Prazeres, P. R. M. A.; Valente, A. J. M.; Lobo, V. M. M.; Burrows, H. D. Binary mutual diffusion coefficients of aqueous solutions of sucrose, lactose, glucose, and fructose in the temperature range from (298.15 to 328.15). J. Chem. Eng. Data 2006, 51, 1836-1840.

(15) Taylor, G. Dispersion of Soluble Matter in Solvent Flowing Slowly through a Tube. Proc. R. Soc. London A 1953, 219, 186-203.

(16) Taylor, G. The dispersion of Matter in Turbulent Flow through a Pipe. Proc. R. Soc. London A 1954, 223, 446-468.

(17) Taylor, G. Conditions Under which Dispersion of a Solute in a Stream of Solvent can be Used to Measure Molecular Diffusion. Proc. $R$. Soc. London A 1954, 225, 473-447.

(18) Callendar, R.; Leaist, D. G. Diffusion Coefficients for Binary, Ternary, and Polydisperse Solutions from Peak-Width Analysis of Taylor Dispersion Profiles. J. Solution Chem. 2006, 35, 353-379.

(19) Barthel, J.; Gores, H. J.; Lohr, C. M.; Seidl, J. J. Taylor dispersion measurements at low electrolyte concentrations. 1. Tetraalkylammonium perchlorate aqueous solutions. J. Solution Chem. 1996, 25, 921935 .

(20) Miyajima, K.; Sawada, M.; Nakagaki, M. Viscosity B-Coefficients, Apparent Molar Volumes, and Activity Coefficients for AlphaCyclodextrin in Aqueous Solutions. Bull. Chem. Soc. Jpn. 1983, 56, $3556-3560$

(21) Lide, D. R. CRC Handbook of Chemistry and Physics, National Bureau of Standards, 64th; CRC Press: Boca Raton, FL, 1984.

Received for review February 26, 2009. Accepted May 19, 2009.

JE900221M 